\title{
SOBRE LAS FUENTES DE "DEL REY ABAJO NINGUNO"
}

En sus consideraciones sobre Del Rey abajo ninguno de Rojas Zorrilla algunos críticos hacen mención de la analogía que tiene esta célebre y popular comedia con otras piezas dramáticas del Siglo de Oro: El villano en su rincón y Peribáñez o el Comendador de Ocaña de Lope de Vega, La luna de la sierra de Vélez de Guevara y El celoso prudente de Tirso de Molina ${ }^{1}$.

Como todavía, que yo sepa, no se han señalado en detalle los posibles puntos esenciales de contacto entre éstas y la obra de Rojas, vale la pena tratar de exponerlos brevemente en este lugar, particularmente porque servirán para completar el cuadro de las fuentes de Rojas y para determinar la importancia de cada una en la elaboración de la pieza.

A su protagonista, García del Castañar, parece que el autor le ha dado una fisonomía de Juan Labrador de El villano... lopesco. Este, como aquél, nunca ha visto al Rey, pero le tiene, sin embargo, en extremada veneración, correspondiendo con suma liberalidad a lo que le pide su monarca. En ambos casos la extrañeza y curiosidad de los príncipes con respecto a esta actitud de parte de sus vasallos se manifiesta por medio de una visita real de incógnito a la casa de los súbditos, donde son invitados a merendar. Delante de ellos, así García como Juan defienden la vida rural en contraste con la de la Corte. En El villano el tema del respeto al Rey constituye la acción principal de la comedia, mientras que en Del Rey abajo ninguno está enlazado con el senti-

a Mesonero Romanos en la introducción de su edición de las Comedias escogidas de Francisco de Rojas Zorrilla (BAAEE, LIV, Madrid, 1886, pág. xIx) cita El Comendador de Ocaña de Lope, La mujer de Peribáñez de Montalván, El celoso prudente de Tirso, La luna de la sierra de Vélez de Guevara. En sus Observaciones preliminares en Obras de Lope de Vega, X, Madrid, I899, pág. LXXI, Menéndez y Pelayo escribe: "Superfluo es advertir que en García del Castañar hay muchas cosas bellísimas que nada tienen que ver con Peribáñez: unas son originales de Rojas, y otras imitadas o adaptadas con mucho talento de varias composiciones más antiguas, especialmente de El villano en su rincón de nuestro Lope, de La luna de la sierra, de Luis Vélez de Guevara, y de El celoso prudente, de Tirso". Al parecer no acepta La mujer de Peribáñez, "fábula exactamente la misma que en la tragicomedia de Lope", como una de las fuentes de Del Rey abajo ninguno. Véase, loc. cit. F. Ruiz Morguende, Francisco de Rojas: Teatro, Madrid, I9 7 , pág. I4, repite la enumeración de las fuentes en las Observaciones preliminares de Menéndez y Pelayo. 
miento del honor: intento de seducir a una esposa honrada, venganza de su marido contra el hombre culpado, seguros indicios de la inocencia de la mujer. De este desarrollo del sentimiento del honor tratan, en cambio, Peribáñez... . La luna ... y El celoso prudente.

Tanto en Peribánez como en Del Rey abajo ninguno presenciamos en las últimas escenas la muerte del causante de la deshonra a manos del hombre ultrajado y la intervención de los dos monarcas en estos episodios, indicaciones probables de una común filiación.

En La luna de la sierra hallamos a un príncipe y a su maestre, ambos enamorados de la villana, Pascuala, esposa de Antón, pareja que nos recuerda al Rey y a don Mendo, de Rojas, no obstante que la atracción del Rey hacia Blanca se limita sólo a expresiones de admiración. Un día, al regresar inesperadamente a su hogar, Antón descubre a dos hombres en el umbral de su casa. Sabe con certeza que uno de ellos es el maestre y sospecha, sin fundamento alguno, que el otro debe de ser el príncipe. Por eso, a pesar de tener en sus manos una escopeta, reprime sus deseos de venganza. Después que los extraños visitantes se van, Antón explica su vacilación a Mendo de esta manera:

Pero la imaginación

de que un príncipe heredero

de Castilla viene allí

me hiela el alma en el pecho.

IOh! respetos inhumanos

de honor, de lealtad, de celos,

de poder, de mujer propia;

dejadme o matadme a un tiempo,

que no hay mayor tormento

que no poder morir y estar muriendo ${ }^{2}$.

Es posible que esta escena haya servido de modelo para aquel pasaje de Del Rey abajo ninguno donde García, regresando inesperadamente, se enfrenta con el intruso Mendo, y pudiéndole matar no lo hace, creyendo que es el Rey. El parecido es, por lo menos, bastante marcado.

Como no puede ofender a su príncipe, García resuelve su conflicto con el plan de matar a doña Blanca, y aquí El celoso prudente de Tirso nos ofrece otra analogía en la escena donde don Sancho se imagina agraviado por el príncipe Segismundo sin la posibilidad de vengarse directamente, puesto que su rival, como él mismo dice:

$$
\begin{aligned}
& \text {... es Príncipe en efeto; } \\
& \text { su sagrado es mi lealtad. }
\end{aligned}
$$

$$
\text { (Escena III, Acto } \text { III }^{3} \text {.) }
$$

2 Véase Luts Vélez de Guevara, Teatro escogido, I. Reinar después de morit. La luna de la sierra. Prólogo y notas de Angel Valbuena Prat. Madrid-Buenos Aires, pág. 254 .

3 En Comedias escogidas de Fray Gabriel Téllez (El Maestro Tirso de Molina), $B A A E E, \mathrm{~V}$, cuarta edición, Madrid, 1903, pág. 628 . 
Como remedio, don Sancho piensa lavar la mancha de su figurada deshonra con la muerte de su esposa, Diana, quemando su casa con ella dentro.

Cada una de estas cuatro comedias, pues, habrá contribuído con ingredientes que sirvieron para la formación de personajes y situaciones. Rojas, como otros contemporáneos suyos, especialmente Moreto, revela ser discípulo fiel de la manera de componer por contaminatio, ideando una pieza original por medio de la fusión de otras obras o de sus partes. Pero, con las comedias citadas todavía no se agotan las fuentes posibles de $\mathrm{Del}$ Rey abajo ninguno. Queda aún la más importante de todas, un episodio en La vida de Marcos de Obregón de Vicente Espinel, que ocupa todo el Descanso Sexto y la primera parte del Descanso Séptimo de la Relación Tercera.

Marcos, que está viajando en compañía de gentes de Milán, se encuentra, después de dejar el pueblo de Crema, con un caballero melancólico que le invita a pasar la noche en su casa. Acabada la cena, este hombre, que se llama Aurelio, le explica la causa de su gran tristeza. Empieza con una evocación nostálgica de su felicidad pasada.

I ) "Nací - dice - inclinado, no a las cortes ni al bullicio popular, que ocupa la vida y entretiene el tiempo, sino a la soledad, usando ejercicios del campo, como es la agricultura, huertas y jardines, pesca y caza de montería y volatería, en que he gastado algunos años y toda mi renta con mucho gusto y algunas buenas obras usadas con caminantes". En este ambiente rústico vivía con su mujer, una hermosísima aldeana, a quien quería entrañablemente, y ella, con un amor igualmente entrañable, le correspondía. "Recogíme con ella a esta casería, donde viví con ella en tanto amor y gusto de su parte y de la mía que no sufría una hora de división" ".

2) Como ejemplo del gran cariño de su mujer hacia él, Aurelio habla de las inquietudes de ella durante su ausencia en las horas de caza, y de cómo solía acogerle cuando volvía. "El día que iba a cazar a la vuelta la hallaba llorosa y con unas ansias y desconsuelos que me regalaban el alma y me obligaban a querella como cosa divina" 5 .

3) Pero una nube muy obscura vino a interponerse de repente entre los dos. Vivía en su casa un músico, medio criado, el cual se puso a galantear a su mujer. Al principio creyó Aurelio que era una "pantasma", pero se enteró al fin de que el que hacía este embeleco era el músico, Cornelio. Un día le llevó consigo a la caza, la que no tuvo buenos resultados, pues, dice Aurelio, "en todo el día no hallé cosa de volatería para las aves ni caza para los perros. Túvelo por mal agüero". En medio de la expedición, Cornelio se fingió enfermo y volvió al pueblo. $\mathrm{Al}$ anochecer volvió a su vez Aurelio y buscó al músico, "vi —añade él- una

4 En Espinel, Vida de Marcos de Obregón. Edición y notas de Samuel Gili Gaya. Madrid, r923, vol. II, págs. 179-182.

5 Loc. cit., pág. 182. 
escalera arrimada a la pared que llegaba hasta mi estancia, y en el remate de la escalera abierto un boquerón por donde cabía un hombre muy bien, que estaba tapado con un lienzo del Ticiano del adulterio de Venus y Marte. Hasta entonces no había creído mi daño. Aparté la escalera de allí con intención que no tuviese por donde bajar, y como un trueno acudí a mi estancia, y llamando para cogellos descuidados mi esposa me vino a abrir la puerta, y él fué muy de priesa a poner los pies en la escalera, y poniéndolos en el aire dió con su persona abajo quebrándose ambas piernas por las rodillas". Bajó también Aurelio y acabó con la vida del miserable dándole de puñaladas y ahorcándole ${ }^{6}$.

4) Continuando su historia, dice Aurelio: "y con la misma furia subiendo a dar de puñaladas a mi esposa se me cayó la daga de las manos y todas cuantas veces intenté hacerlo me hallé incapaz de mover el brazo para herir aquel cuerpo, que tan superior había sido a mis fuerzas" " Un poder sobrenatural estorba el asesinato.

5) Ahora la tiene encerrada, "maniatada de pies y manos" en la presencia de su muerto amante, a quien había sacado el corazón y puesto entre los dos "para que ella viese todos los días el corazón donde tanto a su gusto había vivido". Al terminar su historia Aurelio quiere que Marcos vaya con él para ver a la mujer adúltera. En su presencia ella da pruebas de su inocencia y añade: "Yo no le dije palabra mala [a Cornelio] por sus pretensiones; lo uno porque yo jamás lo he dicho a nadie, lo otro porque después que vió mi entereza no me dijo más palabra deshonesta. Y si me culpare mi esposo y señor porque no le avisé dello, diré que aún viéndolo con enojos muy livianos me despulsaba hasta verle fuera dellos, cuanto más decirle una cosa que tan al alma le había de llegar, y no tenía reino ni imperio el mundo por quien yo manchase mi honra y el lecho de mi esposo y señor" 8 .

6) Sin embargo, a pesar de su clara inocencia, la esposa sabe que la honra de su marido está infamada, y, dirigiéndose a Marcos, le dice con insistencia: "por la piedad que en vos he conocido y por la verdad que os he dicho, os suplico que le roguéis que no me alargue la vida, sino que me abrevie la muerte para que vaya presto a presentar este martirio en la presencia de Dios"9.

Ahora compárense estos seis párrafos con los seis siguientes que se refieren a Del Rey abajo ninguno y se percibirá fácilmente que entre las dos series existen analogías que revelan un íntimo parentesco.

I) Ya hemos observado que García, como el Juan Labrador del Villano en su rincón, afirma en la escena de la merienda su preferencia por la vida rural y su falta de inclinación hacia la cortesana. Sin embargo, previamente, y antes de hablar con el Rey, García nos había pre-

6 Op. cit., págs. I86-87.

7 Op. cit., pág. 187.

8 Op. cit., pág. I9I.

9 Loc. cit., págs. 191-192. 
sentado el mismo contraste combinándolo con el motivo sentimental de la adoración a su esposa. Es el verdadero preludio de la comedia.

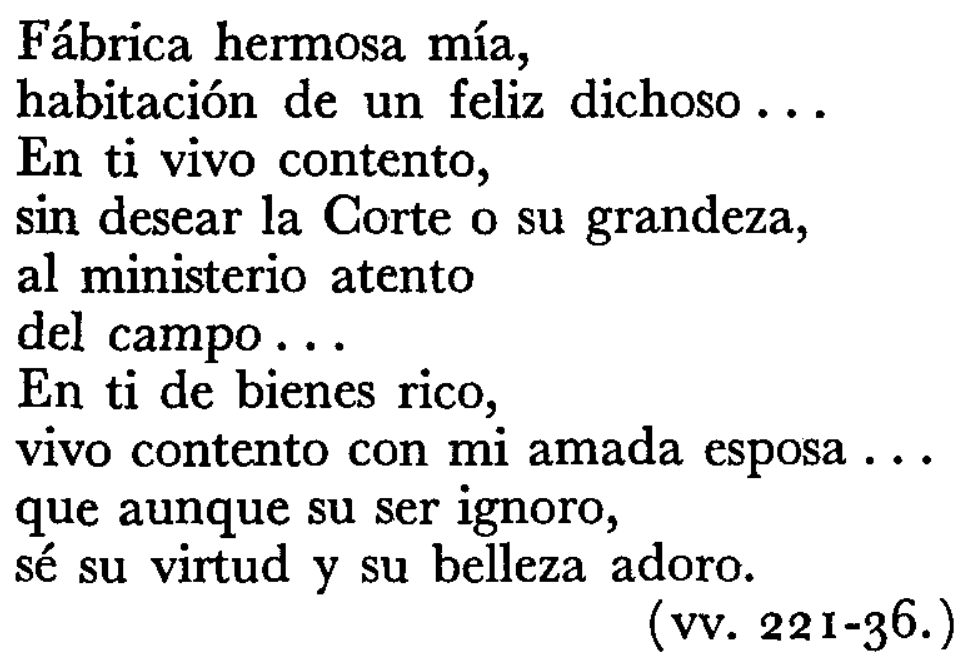

Pues bien, esta combinación solamente está en el episodio de Espinel, y tiene la misma función de preludio ${ }^{10}$.

2) En la Jornada Segunda hallamos a Blanca, que ha trasnochado esperando con ansias y lágrimas la vuelta de García de la caza, y cuando llega su esposo ella le declara:

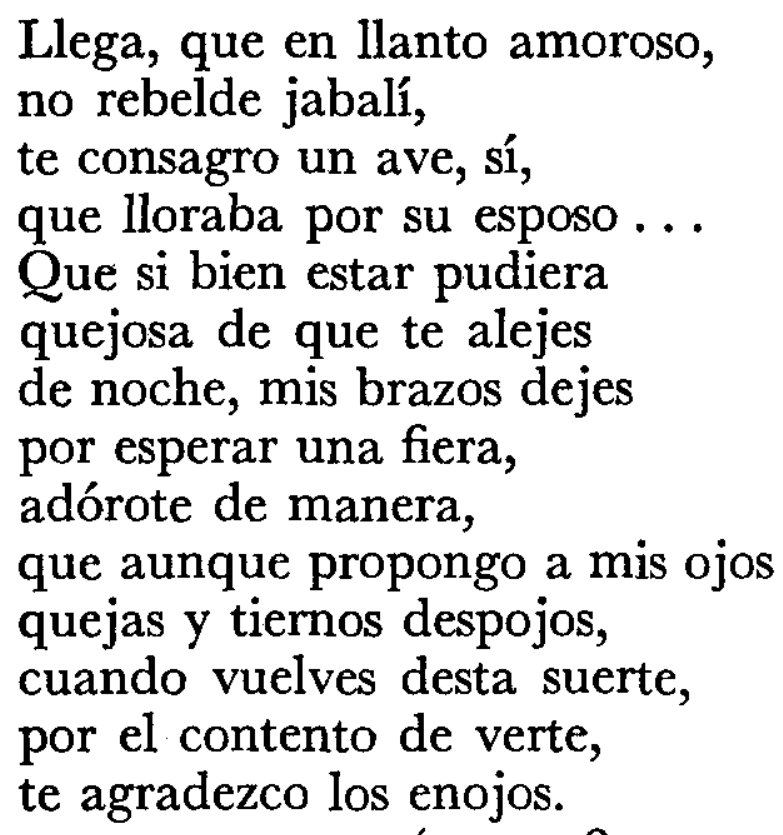

$$
\text { (vv. } 13^{8 I-I 400 .)}
$$

Recordemos que la esposa de Aurelio ya había reaccionado de manera semejante en una situación idéntica.

3) Mientras está cazando de noche, García topa con don Mendo. Un criado de éste lleva una escala, y con ella Mendo entra en la casa por el balcón. Puesto que Mendo le ha estorbado la caza, García regresa a su hogar, en donde halla a su rival, a quien le obliga a bajar por donde ha

. 10 En la expresión de su cariño hacia García, Blanca dice que le adora "como a cosa divina" (v. 313), y Aurelio, hablando de su esposa, asevera que la quería "como cosa divina" (op. cit., pág. I82). En vista de otras analogías parecería un poco extraño si dijéramos que se trata de una pura coincidencia. 
subido. Más tarde, en el palacio del rey, al averiguar que este hombre no es el monarca, García lleva a cabo lo que no había podido hacer antes: matar a su rival. Es evidente que tenemos aquí, sin cambios radicales en la exposición de los detalles, una duplicación de casi todo lo que acontece en una de las partes culminantes de la historia de Aurelio: la caza, el hallarse juntos en el monte marido y galán, estorbo de la caza por la presencia del rival, entrada en la casa por medio de una escala, regreso del marido, salida del intruso por el mismo camino por el cual había venido, y, como castigo de su atrevimiento, la muerte ${ }^{1 \mathrm{1}}$.

4) Después de la salida de don Mendo, García resuelve que la única manera de lavar la mancha de la deshonra que sobre él ha caído es matar a su mujer. En la Jornada Tercera, Blanca da cuenta de lo ocurrido al Conde. Dice que García había entrado en su cuarto, mientras dormía, con la intención de darle muerte, y al llegar:

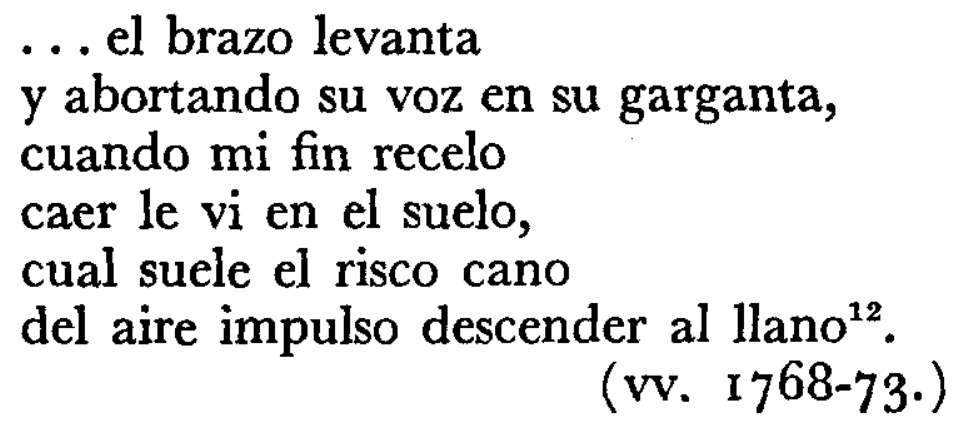

La fuerza misteriosa que salva la vida de doña Blanca es la misma fuerza que libra de la muerte a la esposa de Aurelio.

5) Cuando don Mendo galantea a Blanca durante su primera visita al Castañar, ella calla el incidente, pero en la ocasión del segundo galanteo en el palacio real se da cuenta de la deshonra de su esposo y exclama:

$$
\begin{aligned}
& \text { Ahora sé, caballero, } \\
& \text { que vuestros locos antojos } \\
& \text { son causa de mis enojos } \\
& \text { que sufrir y callar quiero. } \\
& \text { (vv. 21 } 39-44 .)
\end{aligned}
$$

Por el mismo motivo había callado la aldeana anónima.

6) Y, finalmente, Blanca, como nuestra aldeana, por deferencia a la rigurosa ley del pundonor, a pesar de su inocencia declara que está dispuesta a sacrificar su vida, y repite su decisión por lo menos tres veces:

García, guárdete el Cielo, fénix, vive eternamente,

11 Vv. I 147 y sigs.

12 Nota Gili Gaya en su edición, op. cit., II, págs. 187-88: "Recuérdese que García del Castañar siente también su brazo detenido por una fuerza misteriosa cuando va a herir a su esposa. Se trata de un tema corriente en la literatura de entonces". No da más detalles. 
y muera yo, que inocente doy la causa a tu desvelo; que llevaré por consuelo, pues de tu gusto procede, mi muerte; tú vive, y quede viva en tu pecho al partirme...

Ya sé quién eres $\mathrm{y}$, pues tu honra está asegurada con mi muerte, en tu alentada mano blasone tu acero, que aseguró a un caballero y mató a una desdichada; que quiero me des la muerte como lo ruego a tu mano, que si te temí tirano ya te solicito fuerte...

Si he de morir, mi García, no me trates desa suerte, que la dilatada muerte especie es de tiranía... (vv. 2239-2302.)

Por medio de las analogías que hemos aducido podemos percibir que Aurelio, su mujer y Cornelio reaparecen en la comedia bajo los nombres de García, Blanca y don Mendo, sin alteraciones que sean demasiado sustanciales para ocultar por entero sus semejanzas. Hasta Marcos tiene un ligero parecido con el Conde en cuanto que actúa como instrumento para la salvación de la esposa de su huésped. Podemos observar, además, que casi todas las etapas principales en el desarrollo de la historia del pundonor en Del Rey abajo ninguno se hallan en la novela y aproximadamente en el mismo orden. No cabe duda, pues, de que entre las diversas fuentes de la pieza el lugar más importante pertenece al episodio del Marcos de Obregón. Sin embargo, no hay quien deje al mismo tiempo de advertir que frente a esta aparente similitud de contenido se da una notable diversidad desde el punto de vista artístico. La novela intercalada es un relato rápido, de ambiente reducido, con ausencia de lirismo a la vez que débil y artificial en su conclusión. El autor se esfuerza por producir en sus lectores un sentimiento de terror trágico, pero su empeño nos deja indiferentes. En cambio, Rojas en su comedia pone remedio a estas tachas ofreciéndonos un ambiente idílico bastante amplio e interesante, haciendo abundar, aunque con afectación, el elemento lírico, produciendo un terror trágico de poderoso efecto, y dando un término lógico y satisfactorio a su historia, precisamente las características que dan a la comedia el alto valor literario que tiene. En Espinel, Aurelio es un ser vil y despreciable, pero en Rojas está transformado en 
la figura majestuosa de García. A su ennoblecimiento contribuyó sin duda la influencia de Juan Labrador. El realizar esta permutación es de por sí un acierto de suma importancia.

Veamos ahora si es posible dar algunas aclaraciones sobre las fuentes de la historia de Aurelio. Podemos empezar con algunos detalles que sirven para introducirla. Marcos, que ha viajado solo todo el día, "sin saber dónde había de ir a parar, ya que se ponía el sol" ha encontrado a Aurelio quien le invita a pasar la noche en su casa, y allí después de la cena le cuenta su triste historia. Este mismo camino y no muy lejos del "grande edificio" donde fué hospedado Marcos, lo había hecho otro aventurero, Rinaldo, en el Orlando furioso de Ariosto, cantos XLII y XLIII, cuando pasó el Po cerca de Mantua durante su viaje a Lipadusa, donde había de tener lugar el combate de los tres grandes campeones cristianos contra los tres paganos. El también se había encontrado con un caballero cortés cuando anochecía y estaba indeciso sobre si debía pararse o continuar su viaje:

Già s'inchinava il sol molto alla sera, E già apparia nel ciel la prima stella, Quando Rinaldo in ripa alla riviera Stando in pensier, s'avea da mutar sella O tanto soggiornar che l'aria nera Fuggisse inanzi all'altra aurora bella, Venir si vede un cavalliero inanti Cortese ne l'aspetto e nei sembianti.

(XLII, 70.)

El caballero le dió alojamiento en su "gran palazzo" y Rinaldo, al igual que Marcos, cenó con su anfitrión.

En el Orlando furioso (est. 97) nos enteramos de que

Col cortese oste ragionando stava

Il paladino a mensa; e spesso spesso, Senza più differir, gli ricordava

Che gli attenesse quanto avea promesso:

Ed ad or ad or mirandolo, osservava

Ch'avea di grande affanno il core oppresso;

Che non può star momento che non abbia Un cocente sospiro in su le labbia.

(XLII, 97.)

Como vemos, el caballero de Ariosto es voluble a pesar de su tristeza, pero, en cambio, el de Espinel acentúa su disposición de ánimo con un silencio absoluto que a su vez se comunica a Marcos, quien nos informa: "Cené con tanto silencio como el caballero que estaba frontero de mí"13.

${ }^{13}$ Op. cit., pág. 178. 
Rinaldo querría pedir al huésped el cumplimiento de su promesa, antes vagamente manifestada en estas palabras:

Che ti faró veder cosa che debbe

Ben volentier veder chi moglie ha a lato.

(XLII, 72.)

pero no se atreve a hacerlo:

Spesso la voce dal disio cacciata

Viene a Rinaldo sin presso alla bocca

Per domandarlo; e quivi raffrenata

Da cortese modestia, fuor non scocca: ...

(XLII, 98.)

Marcos también quisiera conocer el secreto de Aurelio, pero, como Rinaldo, no se atreve a hacer la pregunta: "Yo no osaba preguntalle cosa, porque el verdadero camino para conservarse los hombres es transformarse en el humor de aquellos con quien tratan ..."

Al fin, acabada la cena, ambos huéspedes relatan sus historias. Estas tienen el mismo tema, la infidelidad de las mujeres, pero, excepto en sus principios, son bastante distintas en sus detalles particulares.

En Espinel, Aurelio cuenta que se había enamorado de una bella aldeana que un día había visto salir por el callejón de unas huertas. La vista de la joven dejó en su corazón "una idea que ni se ha borrado ni se borrará para siempre jamás". Pero ella se encerró en las huertas y rechazó los "presentes, promesas y dádivas" con los cuales Aurelio había tratado de rendirla. Para este comienzo es indudable que el autor tuvo presente esta octava en el cuento del huésped de Rinaldo, que contiene en sí todos los detalles que hemos referido ${ }^{14}$ :
Astringe e lenta a questa terra il morso
Un cavalier giovene, ricco e bello, Che dietro un giorno a un suo falcone iscorso, Essendo capitato entro il mio ostello, Vide la donna e sì nel primo occorso Gli piacque, che nel cor portò il suggello;
$\mathrm{Ne}$ cessò molte pratice far poi $^{15}$,
Per inchinarla ai desideri suoi.

(XLIII, 33.)

\footnotetext{
14 Hasta cierto punto es también claro que Espinel recuerda las circunstancias en que Calixto se enamoró de Melibea, como anota Gili Gaya en su edición, op. cit., pág. 180, pero esta influencia queda como de carácter secundario comparada con la de la octava.

15 Con la opinión de Aurelio: "Parecióme que no sería dificultoso el rendilla a fuerza de presentes, promesas y dádivas, que suelen rendir a las peñas más en-
} 
La imitación de Ariosto que hemos señalado es un caso raro y curioso en que la situación geográfica, en cierto momento de la vida de un autor o de un personaje suyo, ha dictado el desarrollo de una parte de la acción de su obra y la selección de un tema ${ }^{16}$. Ahora Espinel rompe su contacto con el Orlando furioso y funde su cuento con el de la mujer inocente y calumniada que también ha tenido numerosos ecos en la literatura novelesca de varios países.

En efecto, hay un buen número de versiones afines a la relación de Aurelio, entre ellas Florence et Octavien de Rome, la historia de la reina Sevilla, Il libro delle storie di Fioravante, I Reali di Francia de Andrea da Barberino y Le Piacevoli Notti de Straparola (Favola terza, Notte quarta $)^{17}$. Las versiones en la historia de la reina Sevilla, Fioravante e I Reali ... están más íntimamente emparentadas en su contenido y desarrollo que las otras, siendo la de I Reali ... un plagio de la de Fioravante sin cambio en los nombres de los personajes. Los motivos comunes a las tres son: 1) la mujer calumniada, 2) el marido que encuentra al que cree ser galán de su mujer encerrado con ella en su alcoba, 3) la muerte del galán sin consumación o intento de consumar el rapto, 4) muerte del calumniador, 5) el castigo que tiene que sufrir la mujer ultrajada, 6) el perdón y clara inocencia de las tres calumniadas. A ellos hay que añadir otro motivo que se encuentra en I Reali ..., Fioravante y Marcos de Obregón, pero no en la historia de la reina Sevilla ni en

cumbradas" (op. cit., pág. 180), puede compararse lo que dice Rinaldo en el canto XLIII, $49: 3-4$ :

Non sai tu, contra l'oro, che né i marmi

Né 'l durissimo acciar sta alla contesa?

16 Recordemos las versiones españolas más completas del famoso cuento del Curioso impertinente hechas por Timoneda, Villalón, Cervantes y Guillén de Castro.

17 Sobre las filiaciones que existen entre estas versiones se puede consultar la detallada comparación hecha por Pro RajNa en Ricerche intorno ai Reali di Francia, Bologna, 1872, págs. 67-91. Consúltese también G. PARIs, Histoire poétique de Charlemagne, Paris, 1905, págs. 388-98; y Paul Aebischer, Fragments de la "Chanson de la Reine Sibille" et du "Roman de Florence de Rome" conservés aux Archives Cantonales de Sion, en Studi Medievali, n. s. XVI, 1950, págs. 135-ı6o. En España, además de un manuscrito escurialense y dos ediciones de la historia de la Reina Sevilla (Sevilla, 1532 y Burgos, I55I), es bien conocida la versión que se encuentra en La gran conquista de ultramar, Libro primero, caps. 49-66, BAAEE, XLIV, Madrid, I878, págs. 25-36. Me place indicar aquí que el hispanista italiano Grovan ni Calabritro, en su tesis I romanzi picareschi di Mateo Alemán e Vicente Espinel, publicada en Malta en 1929, en nota núm. I7, al cap. vi, La trama del "Marcos de Obregón", pág. I56, ya había sospechado cierta relación entre la historia de Aurelio e I Reali di Francia. Dice alli: "Come si vede, questa novella appartiene al noto ciclo della donna perseguitata, cf. Griselda nel Decameron, la leggenda di Genoveffa, Dionigia nel Pecorone (X, r), Dusolina nei Reali di Francia, la novella in latino di Bartolomeo Fazio, De origine belli inter Gallos et Britannos historia, etc., etc." Algo más sobre el ciclo se puede hallar en L. DI Francia, Novellistica, I, Milano, 1924, págs. 212, 318-19. 
otros cuentos relacionados con ésta, por lo menos en las versiones que yo he podido conocer. Me refiero a los dos milagros u operaciones de una fuerza oculta que producen la salvación de la vida de las mujeres cuando sus respectivos maridos tratan de matarlas, y la repetición del mismo fenómeno para probar la inocencia de las calumniadas. En I Reali di Francia, después de matar al joven que encuentra en la alcoba de su esposa, leemos que Fioravante:

Poi corse al letto e prese Drusolina pe' capelli e tirolla fuori del letto, ed ella nel destar gridó - O Vergine Maria, aiutami! Questa parola fu di tanta grazia che Fioravante le die' della spada e non la potè uccidere nè tagliare le sue carni, e ricorse al letto e prese $e^{\text {' }}$ due figliuoli e per tre volte gli percosse al muro, e non gli potè offendere, tanto miracolo mostrò la madre della vita etterna! Dice alcuno ch'egli corse alla scala e ne tagliò tre scaglioni. Allora disse: "Io veggio ch'io sono ingannato, chè questo è miracolo di Dio" 18 .

Ahora Drusolina es condenada a morir dentro de un horno ardiendo y otra vez se salva milagrosamente con una invocación a Dios ${ }^{19}$. Ya hemos visto cómo quedó misteriosamente paralizado Aurelio cuando por primera vez trató de dar puñaladas a su aldeana. La misma inexplicable impotencia se apodera de él después que la encierra, puesto que nos dice su marido: "Torné a quererla matar y se me tornaron a desjarretar los brazos" ${ }^{20}$.

No pudiendo destruir a Drusolina, la suegra calumniadora consigue su destierro, y después de varias peripecias ocurre el tercer milagro cuando San Marcos en forma de león impide el duelo entre los dos gemelos Ottaviano y Gisberto, revelándoles que son hermanos, hijos de Fioravante y Drusolina. Finalmente el rey queda convencido de la inocencia de su esposa ${ }^{21}$. En Marcos de Obregón la misma fuerza oculta que antes había salvado la vida de la mujer de Aurelio se manifiesta por tercera vez en la acción de los perros que entran por la puerta de la cárcel, los cuales, según Marcos, "en viendo a la desdichada de su esposa llegaron a lamerle las manos y rostro y hacelle tantas caricias que a mí se me enternecieron los ojos y al marido las entrañas y el alma" ${ }^{22}$, prueba concluyen-

18 Véase I Reali di Francia di Andrea da Barberino. Testo critico a cura di Giuseppe Vandelli. Vol. II, parte II, Bologna, 1900, pág. I 79. Cf. también Il libro delle storie di Fioravante en I Reali di Francia, I, Bologna, 1872, pág. 446.

19 Cf. Reali di Francia, op. cit., págs. $184-85$, y Fioravante, op. cit., págs. 449-50.

20 Op. cit., pág. 188.

21 Cf. Reali di Francia, op. cit., págs. 225-26, y Fioravante, op. cit., pág. 474 . Espinel pudo tener la oportunidad de leer la versión en $I$ Reali... en la edición del libro de Andrea da Barberino, Gli Sei Libri dei Reali di Francia... que apareció en Venecia en 1582 , precisamente durante el período de su estancia en Italia.

22 Op. cit., pág. 189 . 
te de su inocencia. En relación a este motivo de la intervención divina o sobrenatural en favor de una inocente todos los otros ocupan un lugar secundario. No faltan, sin embargo, indicios de la influencia de la historia de la reina Sevilla. Uno puede notarse en la concepción de la figura del músico Cornelio. En la historia de la reina el delincuente es un enano, "gordo, e negro, e beçudo, e auía catadura muy mala, e los ojos pequennos, e encouados, e la cabeça muy grande, e las narizes llanas, e las ventanas dellas muy anchas, e las orejas pequennas, e los cabellos erizados, e los braços e las manos como osso, e canos; las piernas tuertas, los pies galindos, e requebrados" ${ }^{23}$. Igualmente antipático es Cornelio, "hombre pequeño de cuerpo, falto de facciones, dientes anchos, manos gruesas, falto de virtudes morales, inclinado a la detracción y cizaña" ${ }^{24}$. Otro indicio es que el intento de seducción de parte de ambos enanos viene a producirse en circunstancias en que los esposos de su víctima están de caza.

En lugar de desterrar a su esposa como lo habían hecho Fioravante y Carlos Maynes, marido de Sevilla, ya sabemos que Aurelio la encerró en un cuarto, y lo hizo con el fin "de matarla con hambre y sed, dándole cada día media libra de pan y muy poca agua" ${ }^{25}$. En la ya citada versión de Straparola hallamos que Chiaretta, la mujer de Ancilotto, rey de Provino, calumniada por la madre de éste, es también condenada de la misma manera: "venne al re pietà di farla morire; ma comandò che fusse posta sotto il luoco dove si lavano le pentole e le scutelle, e che per suo cibo fussero le immondizie e le carogne che giù della fetente $\mathrm{e}$ sozza scaffia cadevano" ${ }^{26}$. La analogía demuestra la posibilidad de que Espinel haya adaptado el detalle leído en una de las ediciones del popular escritor italiano ${ }^{27}$. Finalmente, la idea de hacer de la mujer de Aurelio "hija de muy humildes padres" pudo también ser consecuencia del influjo de esta lectura, ya que Chiaretta es como ella una mujer humilde, hija de un hornero ${ }^{28}$.

Por estas visibles imitaciones, podemos observar que Espinel empleó el viejo procedimiento de la contaminatio en la construcción de su re-

23 Cf. el Cuento del enperador Carlo Maynes, de Rroma, e de la buena enperatriz Seuilla, su muger, en José AMAdor DE los Ríos, Historia crítica de la literatura española, vol. V, Madrid, r864, pág. 344. Es la reproducción del manuscrito escurialense que ya hemos citado.

24 Op. cit., pág. 183 .

25 Op. cit., pág. 188.

26 Cf. Le Piacevoli Notti, op. cit., pág. I8o.

27 Además de varias ediciones italianas, Espinel pudo haber leído a Straparola en tres ediciones españolas; por ejemplo, Primera y segunda parte del honesto $y$ agradable entretenimiento de damas y galanes, compuesto por Francisco Carvacho, Cavallero Napolitano. Traduzida en lengua Toscana en la nuestra vulgar por Francisco Truchado, vecino de la ciudad de Baeça. Granada, 1583, Madrid, 1598, Pamplona, i6r2. Cf. A. Palau y Dulcet, Manual del librero hispano-americano, Barcelona, 1926, VI, pág. $54^{8 .}$

28 Op. cit., pág. 180. 
lato tal como se encuentra utilizado por Rojas al componer su comedia. Sin embargo, es conveniente recalcar que tratándose de un tema de tan grande difusión como el de la mujer calumniada no se podrá excluir en absoluto el empleo de otras versiones intermediarias de parte del autor de Marcos de Obregón, y entre éstas es posible que exista una que contenga juntos todos los elementos principales de la historia de Aurelio.

Con las páginas antecedentes creemos haber hecho una contribución de carácter histórico que ayudará a comprender la génesis del núcleo central de la célebre comedia de Rojas. Pero más importante aún puede ser su significación en el campo de la crítica estética, ya que este conocimiento de la procedencia de las líneas directrices de la pieza pone ante nosotros por primera vez detalles concretos que nos permiten ver cómo y hasta qué punto nuestro autor los ha elaborado en el crisol de su fantasía de gran artista, transformando en poesía la sustancia tosca que había encontrado principalmente en el relato de Aurelio. Esta circunstancia no puede menos de tener el efecto de dar fuerte relieve no sólo a la apreciación de estas partes, sino también a la valorización total de la obra.

Northwestern University.

Joseph G. Fugilla 